\title{
Supporting Information to: Detection and quantification of enteric pathogens in aerosols near open wastewater canals in cities with poor sanitation
}

Olivia Ginn ${ }^{1}$, Lucas Rocha-Melogno ${ }^{2}$, Aaron Bivins ${ }^{1}$, Sarah Lowry ${ }^{3}$, Maria Cardelino ${ }^{4}$, Dennis Nichols ${ }^{5}$, Sachchida Nand Tripathi ${ }^{6}$, Freddy Soria ${ }^{7}$, Marcos Andrade ${ }^{8,9}$, Mike Bergin ${ }^{10}$, Marc A. Deshusses ${ }^{10}$, Joe Brown $^{11^{*}}$

${ }^{1}$ Department of Civil and Environmental Engineering and Earth Science, University of Notre Dame, Notre Dame, Indiana 46656, United States

${ }^{2}$ ICF, 2635 Meridian Parkway Suite 200, Durham, NC, 27713, United States

${ }^{3}$ Department of Civil and Environmental Engineering, Stanford University, Stanford, California, United States

${ }^{4}$ School of Civil and Environmental Engineering, Georgia Institute of Technology, Atlanta, Georgia 30332, United States

${ }^{5}$ Rollins School of Public Health, Emory University, Atlanta, GA, 30322, United States

${ }^{6}$ Department of Civil Engineering \& Centre for Environmental Science and Engineering, Indian Institute of Technology - Kalyanpur, Kanpur, Uttar Pradesh, 208016, India

${ }^{7}$ Centro de Investigación en Agua, Energía y Sostenibilidad, Universidad Católica Boliviana "San Pablo", La Paz, Bolivia

${ }^{8}$ Laboratory for Atmospheric Physics, Institute for Physics Research, Universidad Mayor de San Andres, La Paz, Bolivia

${ }^{9}$ Department of Atmospheric and Oceanic Sciences, University of Maryland, College Park, MD, USA

${ }^{10}$ Department of Civil and Environmental Engineering, and Duke Global Health Institute, Duke University, Durham, North Carolina 27708, United States

${ }^{11}$ Deparment of Environmental Sciences and Engineering, Gillings School of Global Public Health, University of North Carolina, Chapel Hill, North Carolina, 27599-7431, United States

*Corresponding author: Department of Environmental Sciences and Engineering, University of North Carolina, 135 Dauer Drive, Chapel Hill, NC, 27599-7431, United States. Tel: 404385 4579. Email: joebrown@ unc.edu

\section{Contents.}

Tables: 3

Figures: 3

Pages: 21 


\section{Custom TaqMan Array Card (TAC).}

We purchased custom TACs assembled and optimized by Thermo Fisher Scientific (Waltham, MA, USA). The TAC is a 384-well array of $\mu \mathrm{L}$ reaction vessels with dried-down primers and hydrolysis probes for the defined targets for amplification using TaqMan real-time PCR technology. Each array card has 8 ports for loading samples. To prepare the samples for PCR, we mixed $50 \mu \mathrm{L}$ of total nucleic acid template $(0.5 \mu \mathrm{L}$ template per reaction well) with $50 \mu \mathrm{L}$ of qScript XLT 1-Step RT-qPCR ToughMix (Quantabio, Beverly, MA) and filled ports 2-7 with the combined $100 \mu \mathrm{L}$ for each sample. Port 1 was used as a negative control and port 8 was used as a positive control, allowing us to include 6 samples per card. For the NTC we used molecular water extracted using the same protocol as the samples. For the PC template, we used a singleuse aliquot mixture of nucleic acid for each target (gene targets inserted into plasmids) (IDT, Coralville, IA) which were developed using methods previously described ${ }^{1}$

Following the manufacturer's instructions, we centrifuged each card twice at $1200 \mathrm{rpm}$ for one minute, sealed the card, trimmed the loading ports and loaded the card into a QuantStudio 7 (Thermo Fisher Scientific, Waltham, MA). Reverse transcriptase real-time PCR was performed using the following cycling conditions with a $1{ }^{\circ} \mathrm{C} / \mathrm{s}$ ramp rate between all steps: $45^{\circ} \mathrm{C}$ for 10 minutes, $94^{\circ} \mathrm{C}$ for 10 minutes, and then 45 cycles of $94^{\circ} \mathrm{C}$ for 30 seconds and $60^{\circ} \mathrm{C}$ for 1 minute. All positive controls amplified as expected (average $\mathrm{Ct}=27$ across all assays) and we detected MS2 in all samples. Additionally, the TAC included an internal positive control (TaqMan ${ }^{\mathrm{TM}}$ Exogenous Internal Positive Control, Applied Biosystems, Foster City, CA), which we used to monitor for potential inhibition. The internal positive control assay amplified consistently with no indication of inhibition for all air samples (average $\mathrm{Ct}=24$, range $=22-26$ ). We observed positive amplification of our positive control for all assays $(n=32)$. We observed no amplification for any assay in any no template controls $(n=13)$ below a quantification cycle $(\mathrm{Cq})$ of 40 , the cutoff we used for positive detects as has been used previously ${ }^{2,3}$. The threshold of amplification was set for each individual assay at the point of inflection and we interpreted samples as positive if there was a clear distinction between the positive and negative amplification curves 
Table S1. TAC targets, general description, further classification specificity, and pathogenicity.

\begin{tabular}{|c|c|c|c|c|c|}
\hline Category & General description & Further classification & Interpretation & $\begin{array}{l}\text { Assay } \\
\text { reference }\end{array}$ & $\begin{array}{l}\text { Generally } \\
\text { pathogenic in } \\
\text { immunocompetent } \\
\text { hosts }\end{array}$ \\
\hline \multirow{5}{*}{ Bacteria } & Aeromonas & $\begin{array}{l}\text { Aeromonas hydrophila, } \\
\text { caviae, veronii, jandaei, } \\
\text { salmonicida, schubertii, } \\
\text { popofii }\end{array}$ & $\begin{array}{l}\text { If detected, call as } \\
\text { Aeromonas spp. positive }\end{array}$ & 4 & no ${ }^{5}$ \\
\hline & Campylobacter coli & $\begin{array}{l}\text { Campylobacter coli (cadf } \\
\text { gene) }\end{array}$ & $\begin{array}{l}\text { If detected, call as } \\
\text { Campylobacter coli/jejuni } \\
\text { positive }\end{array}$ & 6 & yes $^{7}$ \\
\hline & Clostridium difficile & $\begin{array}{l}\text { Clostridium difficile toxin } \\
\text { A gene tcdA (toxigenic } \\
\text { Clostridium difficile) }\end{array}$ & \multirow[t]{2}{*}{$\begin{array}{l}\text { If either detected, call as } \\
\text { Clostridium difficile } \\
\text { positive. }\end{array}$} & 8 & yes $^{9}$ \\
\hline & Clostridium difficile & $\begin{array}{l}\text { Clostridium difficile toxin } \\
\text { B gene tcdB (toxigenic } \\
\text { Clostridium difficile) }\end{array}$ & & 8 & yes $^{9}$ \\
\hline & Clostridium difficile & $\begin{array}{l}\text { Non-toxigenic } \\
\text { Clostridium difficile when } \\
\text { a non-coding insertion } \\
\text { sequence is present in the }\end{array}$ & $\begin{array}{l}\text { If detected, call as non- } \\
\text { toxigenic Clostridium } \\
\text { difficile positive }\end{array}$ & 10 & no ${ }^{11}$ \\
\hline
\end{tabular}




\begin{tabular}{|c|c|c|c|c|}
\hline & $\begin{array}{l}\text { pathogenicity locus } \\
(\text { PaLoc) }\end{array}$ & & & \\
\hline EAEC & $\begin{array}{l}\text { Enteroaggregative } \\
\text { Escherichia coli (aaiC } \\
\text { gene) }\end{array}$ & \multirow[t]{2}{*}{$\begin{array}{l}\text { If either was detected, call } \\
\text { as EAEC positive }\end{array}$} & 4 & yes $^{12}$ \\
\hline EAEC & $\begin{array}{l}\text { Enteroaggregative } \\
\text { Escherichia coli (aatA } \\
\text { gene) }\end{array}$ & & 13 & yes $^{12}$ \\
\hline EIEC/Shigella & $\begin{array}{l}\text { Enteroinvasive } \\
\text { Escherichia coli/Shigella } \\
\text { (ipaH gene) }\end{array}$ & $\begin{array}{l}\text { If detected, call as } \\
\text { Shigella/EIEC positive }\end{array}$ & 14 & yes $^{15}$ \\
\hline Enterococcus & Enterococcus faecalis & $\begin{array}{l}\text { If detected, call as } E \text {. } \\
\text { faecalis positive }\end{array}$ & 10 & no ${ }^{16}$ \\
\hline Enterococcus & Enterococcus faecium & $\begin{array}{l}\text { If detected, call as } E \text {. } \\
\text { faecium positive }\end{array}$ & 10 & no ${ }^{16}$ \\
\hline EPEC & $\begin{array}{l}\text { Enteropathogenic } \\
\text { Escherichia coli (eae } \\
\text { gene) }\end{array}$ & \multirow[t]{2}{*}{$\begin{array}{l}\text { If either was detected, call } \\
\text { as EPEC positive }\end{array}$} & 4 & yes $^{17}$ \\
\hline EPEC & $\begin{array}{l}\text { Enteropathogenic } \\
\text { Escherichia coli (bfpA } \\
\text { gene) }\end{array}$ & & 4 & yes $^{18}$ \\
\hline LT-ETEC & $\begin{array}{l}\text { Escherichia coli (heat- } \\
\text { labile enterotoxin) }\end{array}$ & $\begin{array}{l}\text { If detected, call as LT- } \\
\text { ETEC positive }\end{array}$ & 19 & yes $^{20}$ \\
\hline ST-ETEC & $\begin{array}{l}\text { Escherichia coli (heat- } \\
\text { stable enterotoxin) }\end{array}$ & $\begin{array}{l}\text { If detected, call as ST- } \\
\text { ETEC positive }\end{array}$ & 4 & yes $^{20}$ \\
\hline
\end{tabular}




\begin{tabular}{|c|c|c|c|c|c|}
\hline & Salmonella spp. & $\begin{array}{l}\text { Salmonella bongori and } \\
\text { all subspecies of } \\
\text { Salmonella enterica }\end{array}$ & $\begin{array}{l}\text { If detected, call as } \\
\text { Salmonella spp. positive }\end{array}$ & 4 & yes $^{21}$ \\
\hline & Shiga-like toxin 1 & $\begin{array}{l}\text { shiga toxin carried by } \\
\text { Shigella dysenteriae; } \\
\text { shiga-like toxin } 1 \text { carried } \\
\text { by Escherichia, } \\
\text { Citrobacter, Aeromonas, } \\
\text { or Enterobacter genus }\end{array}$ & \multirow[t]{2}{*}{$\begin{array}{l}\text { If either was detected, call } \\
\text { as STEC positive }\end{array}$} & 4 & yes $^{22}$ \\
\hline & Shiga-like toxin 2 & $\begin{array}{l}\text { shiga-like toxin } 2 \text { carried } \\
\text { by Escherichia, } \\
\text { Citrobacter, Aeromonas, } \\
\text { or Enterobacter genus }\end{array}$ & & 19 & yes $^{22}$ \\
\hline & Vibrio cholerae & $\begin{array}{l}\text { Vibrio cholerae with or } \\
\text { without the cholera toxin- } \\
\text { encoding gene }\end{array}$ & \multirow[t]{2}{*}{$\begin{array}{l}\text { If detected, call as Vibrio } \\
\text { cholerae positive }\end{array}$} & 4 & $\mathrm{no}^{23}$ \\
\hline & Vibrio cholerae & $\begin{array}{l}\text { Vibrio cholerae carrying } \\
\text { the cholera toxin- } \\
\text { encoding gene }\end{array}$ & & 4,24 & yes $^{25}$ \\
\hline & Yersinia spp. & $\begin{array}{l}\text { all species within the } \\
\text { Yersinia genus }\end{array}$ & $\begin{array}{l}\text { If detected, call as } \\
\text { Yersinia spp. positive }\end{array}$ & 26 & yes $^{16}$ \\
\hline \multirow{2}{*}{ Viruses } & adenovirus 40/41 & $\begin{array}{l}\text { adenovirus serotypes } 40 \\
\text { and } 41\end{array}$ & $\begin{array}{l}\text { If detected, call as } \\
\text { adenovirus } 40 / 41 \text { positive }\end{array}$ & 27 & yes $^{28}$ \\
\hline & pan-adenovirus & $\begin{array}{l}\text { adenovirus serotypes } \\
\text { except } 40 \text { and } 41\end{array}$ & $\begin{array}{l}\text { If detected, call as pan- } \\
\text { adenovirus positive }\end{array}$ & $\begin{array}{l}10 \\
\end{array}$ & no $^{29}$ \\
\hline
\end{tabular}




\begin{tabular}{|c|c|c|c|c|c|}
\hline & pan-astrovirus & $\begin{array}{l}\text { all human serotypes of } \\
\text { astrovirus }\end{array}$ & $\begin{array}{l}\text { If detected, call as pan- } \\
\text { astrovirus }\end{array}$ & 30 & yes $^{31}$ \\
\hline & pan-enterovirus & $\begin{array}{l}\text { all enterovirus serotypes } \\
\text { with the enterovirus genus }\end{array}$ & $\begin{array}{l}\text { If detected, call as pan- } \\
\text { enterovirus }\end{array}$ & 24 & no ${ }^{32}$ \\
\hline & norovirus GI & norovirus GI & $\begin{array}{l}\text { If detected, call as } \\
\text { norovirus GI positive }\end{array}$ & 33 & yes \\
\hline & norovirus GII & norovirus GII & $\begin{array}{l}\text { If detected, call as } \\
\text { norovirus GII positive }\end{array}$ & 34 & yes \\
\hline & rotavirus & rotavirus $\mathrm{A}$ & $\begin{array}{l}\text { If detected, call as } \\
\text { rotavirus A positive }\end{array}$ & 35 & yes \\
\hline & rotavirus & rotavirus B & $\begin{array}{l}\text { If detected, call as } \\
\text { rotavirus B positive }\end{array}$ & 10 & yes \\
\hline & rotavirus & rotavirus $\mathrm{C}$ & $\begin{array}{l}\text { If detected, call as } \\
\text { rotavirus } \mathrm{C} \text { positive }\end{array}$ & 10 & yes \\
\hline & rotavirus & rotavirus non-typable & $\begin{array}{l}\text { If detected, call as pan- } \\
\text { rotavirus }\end{array}$ & 10 & yes \\
\hline & sapovirus V & $\begin{array}{l}\text { sapovirus belonging to } \\
\text { genogroup V }\end{array}$ & $\begin{array}{l}\text { If either detected, call as } \\
\text { Sapovirus positive }\end{array}$ & 4 & yes $^{36}$ \\
\hline & sapovirus I, II, or IV & $\begin{array}{l}\text { sapovirus belonging to } \\
\text { genogroups I, II, or IV }\end{array}$ & & 4 & yes $^{36}$ \\
\hline & Cryptosporidium & Cryptosporidium parvum & $\begin{array}{l}\text { If detected, call as } \\
\text { Cryptosporidium parvum } \\
\text { positive }\end{array}$ & 37 & yes \\
\hline Fivtuzod & Entamoeba histolytica & Entamoeba histolytica & $\begin{array}{l}\text { If detected, call as } \\
\text { Entamoeba histolytica } \\
\text { positive }\end{array}$ & 38 & yes \\
\hline
\end{tabular}




\begin{tabular}{|c|c|c|c|c|c|}
\hline & Giardia & Giardia duodenalis & $\begin{array}{l}\text { If detected, call as Giardia } \\
\text { duodenalis positive }\end{array}$ & 38 & yes \\
\hline \multirow[t]{2}{*}{ Helminths } & Trichuris & Trichuris trichiura & $\begin{array}{l}\text { If detected, call as } \\
\text { Trichuris trichiura } \\
\text { positive }\end{array}$ & 39 & yes \\
\hline & Ascaris & Ascaris lumbricoides & $\begin{array}{l}\text { If detected, call as Ascaris } \\
\text { lumbricoides positive }\end{array}$ & 40 & yes \\
\hline \multirow[b]{2}{*}{ Controls } & --- & Internal Positive Control & $\begin{array}{l}\text { If detected in all rows, } \\
\text { assume no inhibition }\end{array}$ & 10 & --- \\
\hline & --- & $\begin{array}{l}\text { MS2 Phage (extraction } \\
\text { control) }\end{array}$ & $\begin{array}{l}\text { If detected in all rows, } \\
\text { consider extraction } \\
\text { successful }\end{array}$ & 41 & --- \\
\hline
\end{tabular}




\section{Quantitative molecular assays: ddPCR.}

For density estimation, we conducted absolute quantification of 12 enteric pathogen targets in highvolume aerosol samples via Droplet Digital PCR (ddPCR; QX200 Droplet Digital PCR System, Bio-Rad, Hercules, CA, USA). Targets included nucleic acids associated with selected viruses (adenovirus A-F, pan-enterovirus, norovirus GI, and norovirus GII), bacteria (Campylobacter jejuni, Shigella/EIEC, STETEC, and two targets for Salmonella spp.), and protozoa (Cryptosporidium spp. and Giardia duodenalis) and are detailed in SI Table 2. We screened all primer, probe, and control sequences in NCBI BLASTn to confirm reported specificities and ordered all control genetic materials from Integrated DNA Technologies (Coralville, IA).

We confirmed assay performance in our specific sample matrix (bioaerosols) by experimentally determining $95 \%$ limits of detection (LODs) for each assay using a ten-replicate serial dilution series of positive control material and a probit analysis outlined by Stokdyk et. al. ${ }^{42,43} \mathrm{We}$ incubated control materials at $50^{\circ} \mathrm{C}$ for $20 \mathrm{~min}$, hydrated according to manufacturer instructions, and performed a serial dilution. We vortexed for 15 seconds between every transfer and made sure to pipetting depth was consistent across the dilution. We used these replicates to calculate the 95\% LOD which represents the concentration for which the probability of a single ddPCR reaction being positive is $95 \%$. Positive control sequences, primers, probes, and experimentally determined 95\% LODs are detailed for each assay in Table S2.

Before ddPCR for RNA targets (detailed in SI Table 2), we performed reverse transcription (RT) of RNA to cDNA with a High Capacity cDNA Reverse Transcription Kit with RNase Inhibitor (ThermoFisher Scientific, Waltham, MA). Following the manufacturer's instructions, we added $10 \mu \mathrm{L}$ of nucleic acid extract to $10 \mu \mathrm{L}$ of RT master mix and loaded the $20 \mu \mathrm{L}$ reaction on to the thermal cycler with the following conditions: 1) 10 minutes at $25^{\circ} \mathrm{C}$, 2) 120 minutes at $\left.37^{\circ} \mathrm{C}, 3\right) 4 \mathrm{~min}$ at $85^{\circ} \mathrm{C}$ and 5) infinite hold at $4{ }^{\circ} \mathrm{C}$. We stored the resulting cDNA at $-80^{\circ} \mathrm{C}$ until further molecular analysis. We assumed $100 \%$ efficiency and reverse ddPCR results were then multiplied by a 0.5 factor to account for the $1: 2$ dilution of extract. In interpreting assays that underwent reverse transcription, we first assessed the positive detection and amplification of the process control spike of RNA virus BRSV via the Inforce 3 bovine vaccine in each sample. We stored cDNA at $-20^{\circ} \mathrm{C}$ until analysis within a week. 
During ddPCR, the PCR reaction is partitioned into thousands of individual reaction partitions before amplification using QX200 Droplet Generator, sealed using the PX1 PCR Plate Sealer, amplified using the C1000 Touch Thermal Cycler and analyzed at end-point with the QX200 Droplet Reader to enable absolute quantification of target DNA or cDNA (Bio-Rad, Hercules, CA, USA). Unlike qPCR, no standard curve is necessary as targets are quantitatively estimated using a most-probable number technique based on the Poisson distribution and the observed proportion of droplets positive for the target of interest ${ }^{44}$. We conduct manual thresholding based on classification of positive or negative droplets using QuantaSoft (V1.7.4; BioRad, Hercules, CA).

For probe-based assays, we set reaction mixes to a total volume of $20 \mu \mathrm{L}$ including $0.5 \mu \mathrm{L}$ each of forward and reverse primer for a final concentration of $900 \mathrm{nM} ; 0.05 \mu \mathrm{L}$ of probe for a final concentration of $250 \mathrm{nM} ; 10 \mu \mathrm{L}$ of $2 \mathrm{X}$ Supermix for Probes (Bio-Rad, Hercules, CA, USA), $5 \mu \mathrm{L}$ of molecular grade water, and $4 \mu \mathrm{L}$ of extract. The only assay not using a probe-based assay was $E$. coli $(y b b W)$ for which we used EvaGreen chemistry in a total reaction volume of $20 \mathrm{uL}$ that included $1 \mu \mathrm{L}$ each of forward and reverse primers for final concentrations of $250 \mathrm{nM} ; 10 \mu \mathrm{L}$ of $2 \mathrm{X}$ EvaGreen Supermix (Bio-Rad, Hercules, $\mathrm{CA}, \mathrm{USA}) ; 4 \mu \mathrm{L}$ of molecular grade water, and $4 \mu \mathrm{L}$ of extract (Supporting Information). We performed each ddPCR experiment using the Bio-Rad QX200 Droplet Digital PCR System and C1000 Touch Thermal Cycler (Bio-Rad, Hercules, CA, USA). On each ddPCR plate, we included two positive controls, two sample blank controls (extracted elution buffer) and two no-template controls using molecular-grade water to control for contamination via human or other error and to detect false positives. 
Table S2. ddPCR assay specs, thermocycling conditions, and 95\% limits of detection (95\% LOD).

\begin{tabular}{|c|c|c|c|c|c|c|c|c|c|c|}
\hline Target & $\begin{array}{l}\text { Referenc } \\
\text { e }\end{array}$ & Gene & RT & Primers & Probe & Sequence position & Amplicon length & $\begin{array}{l}\text { Thermal Cycling } \\
\text { Conditions }\end{array}$ & $\begin{array}{c}5 \% \\
\text { LOD } \\
\text { (gc/reacti } \\
\text { on) }\end{array}$ & $\begin{array}{l}\text { Gen bank } \\
\text { accession }\end{array}$ \\
\hline $\begin{array}{l}\text { Bovine } \\
\text { respiratory } \\
\text { syncytial virus }\end{array}$ & 45 & $\begin{array}{l}\text { beta- } \\
\text { actin }\end{array}$ & Yes & $\begin{array}{l}\text { F:GCAATGCTGCAGGAC } \\
\text { TAGGTATAAT } \\
\text { R:ACACTGTAATTGATG } \\
\text { ACCCCATTCT }\end{array}$ & $\begin{array}{l}\text { 5'- /56- } \\
\text { FAM/ACCAAGACT/ } \\
\text { ZEN/TGTATGATGC } \\
\text { TGCCAAAGCA/3IA } \\
\text { BkFQ/ -3' }\end{array}$ & $\begin{array}{l}\text { F: } 992-1016 \\
\text { R: } 1115-1091 \\
\text { P: } 1043-1061\end{array}$ & 124 & $\begin{array}{l}95 \text { C } 10 \text { min; } \\
95 \text { C 30s, 56.6 C } 2 \\
\min (40 \mathrm{x}) ; \\
98 \text { C } 10 \mathrm{~min} ; 4 \text { C hold }\end{array}$ & -- & $\begin{array}{l}\mathrm{AF} 29554 \\
4.1\end{array}$ \\
\hline $\begin{array}{l}\text { Shigella/Enteroi } \\
\text { nvasive } E \text {. coli } \\
\text { (EIEC) }\end{array}$ & 46 & $i p a H$ & No & $\begin{array}{l}\text { F:ACCATGCTCGCAGAG } \\
\text { AAACT } \\
\text { R:TACGCTTCAGTACAG } \\
\text { CATGC }\end{array}$ & $\begin{array}{l}\text { 5'- } \\
\text { /5HEX/TGGCGTGTC } \\
\text { /ZEN/GGGAGTGAC } \\
\text { AGC/3IABkFQ/ -3' }\end{array}$ & $\begin{array}{l}\text { F: } 1345-1364 \\
\text { R: } 1525-1506 \\
\text { P: } 1401-1421\end{array}$ & 181 & $\begin{array}{l}95 \text { C } 10 \mathrm{~min} ; \\
95 \text { C 30s, 58.7 C } 2 \\
\min (40 \mathrm{x}) ; \\
98 \text { C } 10 \mathrm{~min} ; 4 \mathrm{C} \text { hold }\end{array}$ & 2.02 & M76445.1 \\
\hline $\begin{array}{l}\text { Heat Stabile } \\
\text { Enterotoxigenic } \\
\text { E. coli (ST- } \\
\text { ETEC) }\end{array}$ & 47 & STh & No & $\begin{array}{l}\text { F:TCCTGAAAGCATGAA } \\
\text { TAGTAGCAATTAC } \\
\text { R:TTAATAGCACCCGGT } \\
\text { ACAAGCA }\end{array}$ & $\begin{array}{l}\text { 5-' /56- } \\
\text { FAM/ACAACACAA } \\
\text { TTCACAGCA/3MGB } \\
\text { EC/ -3' }\end{array}$ & $\begin{array}{l}\text { F: } 171-198 \\
\text { R: } 243-222 \\
\text { P: } 268-291\end{array}$ & 73 & $\begin{array}{l}95 \text { C } 10 \text { min; } \\
94 \text { C 30s, 54.6 C } 1 \\
\text { min (40x); } \\
98 \text { C } 10 \text { min; } 4 \text { C hold }\end{array}$ & 5.07 & M29255.1 \\
\hline $\begin{array}{l}\text { Campylobacter } \\
\text { jejuni }\end{array}$ & 48 & тарА & No & $\begin{array}{l}\text { F: } \\
\text { CTGGTGGTTTTGAAGCA } \\
\text { AAGATT } \\
\text { R:CAATACCAGTGTCTA } \\
\text { AA } \\
\text { GTGCGTTTAT }\end{array}$ & $\begin{array}{l}\text { 5'- } \\
\text { /6FAM/TTGAATTCC } \\
\text { AACATCGCTAATG } \\
\text { TATAAAAGCCCTT } \\
\text { T/MGBNFQ/ -3' }\end{array}$ & $\begin{array}{l}\text { F: } 307-329 \\
\text { R: } 402-376 \\
P: 330-365\end{array}$ & 95 & $\begin{array}{l}95 \text { C } 10 \text { min; } \\
95 \text { C 30s, 58.7 C } 1 \\
\min (40 \mathrm{x}) ; \\
98 \text { C } 10 \mathrm{~min} ; 4 \text { C hold }\end{array}$ & 3.40 & X80135.1 \\
\hline Salmonella sp. & 49 & $t t r$ & No & $\begin{array}{l}\text { F: } \\
\text { CTCACCAGGAGATTAC } \\
\text { AACATGG } \\
\text { R: } \\
\text { AGCTCAGACCAAAAGT } \\
\text { GACCATC }\end{array}$ & $\begin{array}{l}\text { 5'- /56- } \\
\text { FAM/AAAGTCGGT/ } \\
\text { ZEN/CTCGCCGTCG } \\
\text { GTG/3IABkFQ/ -3' }\end{array}$ & $\begin{array}{l}\text { F: } 4287-4309 \\
\text { R: } 4381-4359 \\
\text { P: } 4336-4357\end{array}$ & 95 & $\begin{array}{l}\text { 95C } 10 \text { min; } \\
95 \text { C 30s, 59.9 C } 1 \\
\text { min (40x); } \\
98 \text { C } 10 \text { min; } 4 \text { C hold }\end{array}$ & 3.77 & $\begin{array}{l}\text { AF28226 } \\
8\end{array}$ \\
\hline
\end{tabular}




\begin{tabular}{|c|c|c|c|c|c|c|c|c|c|c|}
\hline & & & & $\mathrm{F}:$ & & & & & & \\
\hline Salmonella sp. & 50 & invA & No & $\begin{array}{l}\text { TCGTCATTCCATTACCT } \\
\text { ACC } \\
\text { R: } \\
\text { AAACGTTGAAAAACTG } \\
\text { AGGA }\end{array}$ & $\begin{array}{l}\text { 5'- } \\
\text { /5HEX/TCTGGTTGA } \\
\text { /ZEN/TTTCCTGATC } \\
\text { GCA/3IABkFQ/ -3' }\end{array}$ & $\begin{array}{l}\text { F: } 167-186 \\
\text { R: } 285-234 \\
\text { P: } 189-210\end{array}$ & 118 & $\begin{array}{l}95 \text { C } 10 \text { min; } \\
94 \text { C } 30 \text { s, } 51.2 \text { C } 1 \\
\min (40 \mathrm{x}) ; \\
98 \text { C } 10 \text { min; } 4 \text { C hold }\end{array}$ & 1.71 & M90846 \\
\hline E. coli & 51 & $y b b W$ & No & $\begin{array}{l}\text { F: } \\
\text { TGATTGGCAAAATCTGG } \\
\text { CCG } \\
\text { R:GAAATCGCCCAAATC } \\
\text { GCCAT }\end{array}$ & $\mathrm{n} / \mathrm{a}$ & $\begin{array}{l}\text { F: } 538033-538052 \\
\text { R: } 538224-538243\end{array}$ & 211 & $\begin{array}{l}95 \text { C } 10 \text { min; } \\
95 \text { C 30s, 59 C } 1.5 \\
\min (40 \mathrm{x}) ; \\
\text { 4 C } 5 \text { min; } 90 \text { C } 5 \\
\min ; 4 \text { C hold }\end{array}$ & 7.58 & $\begin{array}{l}\text { NC_0009 } \\
13.3\end{array}$ \\
\hline $\begin{array}{l}\text { Giardia } \\
\text { duodenalis }\end{array}$ & 52 & $\begin{array}{l}\text { Beta- } \\
\text { giardin }\end{array}$ & No & $\begin{array}{l}\text { F:GGCCCTCAAGAGCCT } \\
\text { GAAC } \\
\text { R:GGGCGATCGTCTCCTT } \\
\text { CTC }\end{array}$ & $\begin{array}{l}\text { 5'- } / 56- \\
\text { FAM/CTCGAGACA } \\
\text { GGCATC/3MGBEC/ } \\
-3^{\prime}\end{array}$ & $\begin{array}{l}\text { F: } 402-420 \\
\text { R: } 544-526 \\
\text { P: } 268-291\end{array}$ & 143 & $\begin{array}{l}95 \text { C } 10 \text { min; } \\
95 \text { C 30s, } 58.7 \text { C } 1 \\
\min (40 \mathrm{x}) ; \\
98 \text { C } 10 \mathrm{~min} \text {; } 4 \text { C hold }\end{array}$ & 2.85 & $\begin{array}{l}\text { AY07272 } \\
7\end{array}$ \\
\hline $\begin{array}{l}\text { Cryptosporidum } \\
\text { sp. }\end{array}$ & 4,53 & $\begin{array}{l}18 S \\
r R N A\end{array}$ & No & $\begin{array}{l}\text { F:GGGTTGTATTTATTAG } \\
\text { ATAAAGAACCA } \\
\text { R:AGGCCAATACCCTAC } \\
\text { CGTCT }\end{array}$ & $\begin{array}{l}\text { 5'- } \\
\text { /5HEX/TGACATATC } \\
\text { ATTCAAGTTTCTG } \\
\text { AC/3MGBEC/ - } 3 \text { ' }\end{array}$ & $\begin{array}{l}\text { F: } 197-223 \\
\text { R: } 322-303 \\
P: 268-291\end{array}$ & 80 & $\begin{array}{l}95 \text { C } 10 \mathrm{~min} ; \\
94 \text { C 30s, } 54.6 \text { C } 1 \\
\min (40 \mathrm{x}) ; \\
98 \text { C } 10 \mathrm{~min} ; 4 \mathrm{C} \text { hold }\end{array}$ & 1.71 & $\begin{array}{l}\text { AF09349 } \\
1.1\end{array}$ \\
\hline norovirus GII & 34 & $\begin{array}{l}\text { ORF 1- } \\
2 \\
\text { junctio } \\
n\end{array}$ & Yes & $\begin{array}{l}\text { F:CARGARBCNATGTTY } \\
\text { AGRTGGATGAG } \\
\text { R:TCGACGCCATCTTCAT } \\
\text { TCACA }\end{array}$ & $\begin{array}{l}\text { 5'- /56- } \\
\text { FAM/TGGGAGGGC/ } \\
\text { ZEN/GATCGCAATC } \\
\text { T/3IABkFQ/ -3' }\end{array}$ & $\begin{array}{l}\text { F: } 5003-5028 \\
\text { R: } 5100-5080 \\
\text { P: } 5048-5067\end{array}$ & 98 & $\begin{array}{l}95 \text { C } 10 \text { min; } \\
95 \text { C 30s, 54.6 C } 1 \\
\min (40 \mathrm{x}) ; \\
98 \text { C } 10 \mathrm{~min} ; 4 \mathrm{C} \text { hold }\end{array}$ & 4.66 & $\begin{array}{l}\text { AF14589 } \\
6.1\end{array}$ \\
\hline pan-enterovirus & 54,55 & $\begin{array}{l}\text { EntV F' } \\
\text { UTR }\end{array}$ & Yes & $\begin{array}{l}\text { F: } \\
\text { CCTCCGGCCCCTGAATG } \\
\text { R:ACCGGATGGCCAATC } \\
\text { CAA }\end{array}$ & $\begin{array}{l}\text { 5'- /56- } \\
\text { FAM/CGGAACCGA/ } \\
\text { ZEN/CTACTTTGGG } \\
\text { TGTCCGT/3IABkFQ/ } \\
-3^{\prime}\end{array}$ & $\begin{array}{l}\text { F: } 424-440 \\
\text { R: } 619-602 \\
\text { P: } 512-537\end{array}$ & 196 & $\begin{array}{l}95 \text { C } 10 \text { min; } \\
95 \text { C 30s, 56.2 C } 2 \\
\min (40 \mathrm{x}) ; \\
98 \text { C } 10 \mathrm{~min} ; 4 \text { C hold }\end{array}$ & 1.72 & $\begin{array}{l}\text { MW0306 } \\
42.1\end{array}$ \\
\hline norovirus GI & 33 & $\begin{array}{l}\text { ORF1- } \\
\text { ORF2 }\end{array}$ & Yes & $\begin{array}{l}\text { F:GCCATGTTCCGNTGGA } \\
\text { TG } \\
\text { R:TCCTTAGACGCCATCA } \\
\text { TCAT }\end{array}$ & $\begin{array}{l}\text { /5HEX/TGTGGACA } \\
\text { G/ZEN/GAGATCGC } \\
\text { AATCTC/3IABkFQ/ }\end{array}$ & $\begin{array}{l}\text { F: } 5266-5283 \\
\text { R: } 5361-5342 \\
\text { P: } 5303-5325\end{array}$ & 96 & $\begin{array}{l}95 \text { C } 10 \mathrm{~min} ; \\
95 \text { C 30s; } 54.6 \mathrm{C} 1 \\
\min (40 \mathrm{x}) ; \\
98 \text { C } 10 \mathrm{~min} ; 4 \mathrm{C} \text { hold }\end{array}$ & 2.30 & $\begin{array}{l}\text { MG04969 } \\
3.1\end{array}$ \\
\hline
\end{tabular}




\begin{tabular}{|c|c|c|c|c|c|c|c|c|c|c|}
\hline & & & & F:GGACGCCTCGGAGTA & & & & & & \\
\hline adenovirus A-F & 27 & $\begin{array}{l}\text { hexon/J } \\
T V X\end{array}$ & Yes & $\begin{array}{l}\text { CC } \\
\text { TGAG } \\
\text { R:ACNGTGGGGTTTCTG } \\
\text { AA } \\
\text { CTTGTT }\end{array}$ & $\begin{array}{l}\text { 5'- /56- } \\
\text { FAM/CTGGTGCAG/ } \\
\text { ZEN/TTCGCCCGTG } \\
\text { CCA/3IABkFQ/ - -3' }\end{array}$ & $\begin{array}{l}\text { F: } 18895-18915 \\
\text { R: } 18990-18968 \\
\text { P: 18923: } 18944\end{array}$ & 96 & $\begin{array}{l}95 \text { C } 10 \text { min; } \\
95 \text { C 30s, 58.7 C } 2 \\
\min (40 \mathrm{x}) ; \\
98 \text { C } 10 \mathrm{~min} ; 4 \text { C hold }\end{array}$ & 4.31 & $\begin{array}{l}\text { AC_0000 } \\
08\end{array}$ \\
\hline MS2 & 41 & MS2g1 & No & $\begin{array}{l}\text { F: } \\
\text { TGGCACTACCCCTCTCC } \\
\text { GTATTCACG } \\
\text { R:GTACGGGCGACCCCA } \\
\text { CG } \\
\text { ATGAC }\end{array}$ & $\begin{array}{l}\text { 5'- } \\
\text { /5HEX/CACATCGAT } \\
\text { /ZEN/AGATCAAGG } \\
\text { TGCCTACAAGC/3I } \\
\text { ABkFQ/ '3' }\end{array}$ & $\begin{array}{l}\text { F: } 160-185 \\
\text { R: } 358-237 \\
\text { P: } 201-229\end{array}$ & 99 & $\begin{array}{l}\text { 95C } 10 \mathrm{~min} ; \\
95 \mathrm{C} 30 \mathrm{~s}, 59.9 \mathrm{C} 1 \\
\min (40 \mathrm{x}) ; \\
98 \text { C } 10 \mathrm{~min} ; 4 \mathrm{C} \text { hold }\end{array}$ & 3.15 & $\begin{array}{l}\text { NC_0014 } \\
17\end{array}$ \\
\hline
\end{tabular}

Table S3: Model results for samples in La Paz and Kanpur. In in the linear regression analyses of meteorological variable effects on target density, multivariable models were conducted first to narrow down meaningful variables. Subsequently, individual linear regression models were conducted and only the variables that were the most meaningful are reported.

\begin{tabular}{|c|c|c|c|c|c|c|c|c|c|c|c|c|}
\hline & \multicolumn{12}{|c|}{ Relevant Effect Models } \\
\hline & \multicolumn{6}{|c|}{ La Paz } & \multicolumn{6}{|c|}{ Kanpur } \\
\hline & \multicolumn{2}{|c|}{$\begin{array}{c}\text { Unpaired Two- } \\
\text { Samples Wilcoxon } \\
\text { Test: Season (rainy } \\
\text { or dry) }\end{array}$} & \multicolumn{2}{|c|}{$\begin{array}{l}\text { Unpaired Two- } \\
\text { Samples Wilcoxon } \\
\text { Test: Time of day } \\
\text { (morning or } \\
\text { afternoon) }\end{array}$} & \multicolumn{2}{|c|}{$\begin{array}{l}\text { Linear regression } \\
\text { analysis: effect of } \\
\text { temperature in the } \\
\text { morning }\end{array}$} & \multicolumn{2}{|c|}{$\begin{array}{c}\text { Unpaired Two- } \\
\text { Samples Wilcoxon } \\
\text { Test: Season (rainy } \\
\text { or dry) }\end{array}$} & \multicolumn{2}{|c|}{$\begin{array}{l}\text { Unpaired Two- } \\
\text { Samples Wilcoxon } \\
\text { Test: Time of day } \\
\text { (morning or } \\
\text { afternoon) }\end{array}$} & \multicolumn{2}{|c|}{$\begin{array}{l}\text { Linear regression } \\
\text { analysis: effect of } \\
\text { relative humidity }\end{array}$} \\
\hline Target & $\mathrm{p}$-value & $\begin{array}{l}\text { effect } \\
\text { size } \\
\end{array}$ & $\mathrm{p}$-value & $\begin{array}{l}\text { effect } \\
\text { size }\end{array}$ & $\mathrm{p}$-value & $\begin{array}{l}\text { adjusted } \\
\mathrm{R}^{2}\end{array}$ & $\mathrm{p}$-value & $\begin{array}{l}\text { effect } \\
\text { size }\end{array}$ & $\mathrm{p}$-value & $\begin{array}{l}\text { effect } \\
\text { size } \\
\end{array}$ & $\mathrm{p}$-value & $\begin{array}{l}\text { adjusted } \\
\mathrm{R}^{2}\end{array}$ \\
\hline adenovirus $\mathrm{A}-\mathrm{F}$ & 0.64 & 0.058 & 0.40 & 0.11 & 0.0043 & 0.18 & 0.16 & 0.20 & 0.81 & 0.034 & 0.39 & -0.0061 \\
\hline ST-ETEC & 0.49 & 0.082 & 0.22 & 0.15 & 0.0050 & 0.18 & 0.090 & 0.23 & 0.49 & 0.097 & 0.68 & -0.021 \\
\hline
\end{tabular}




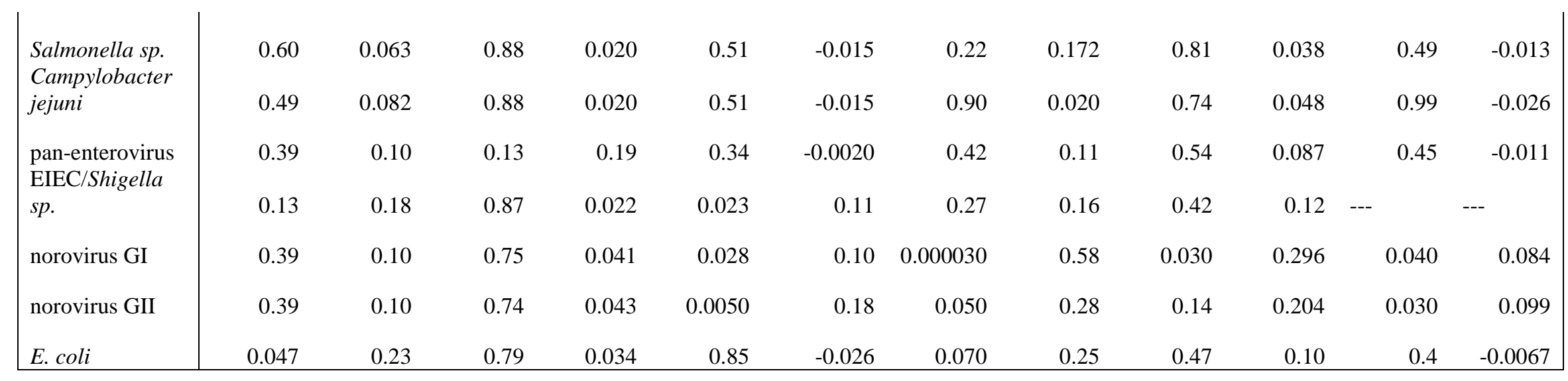




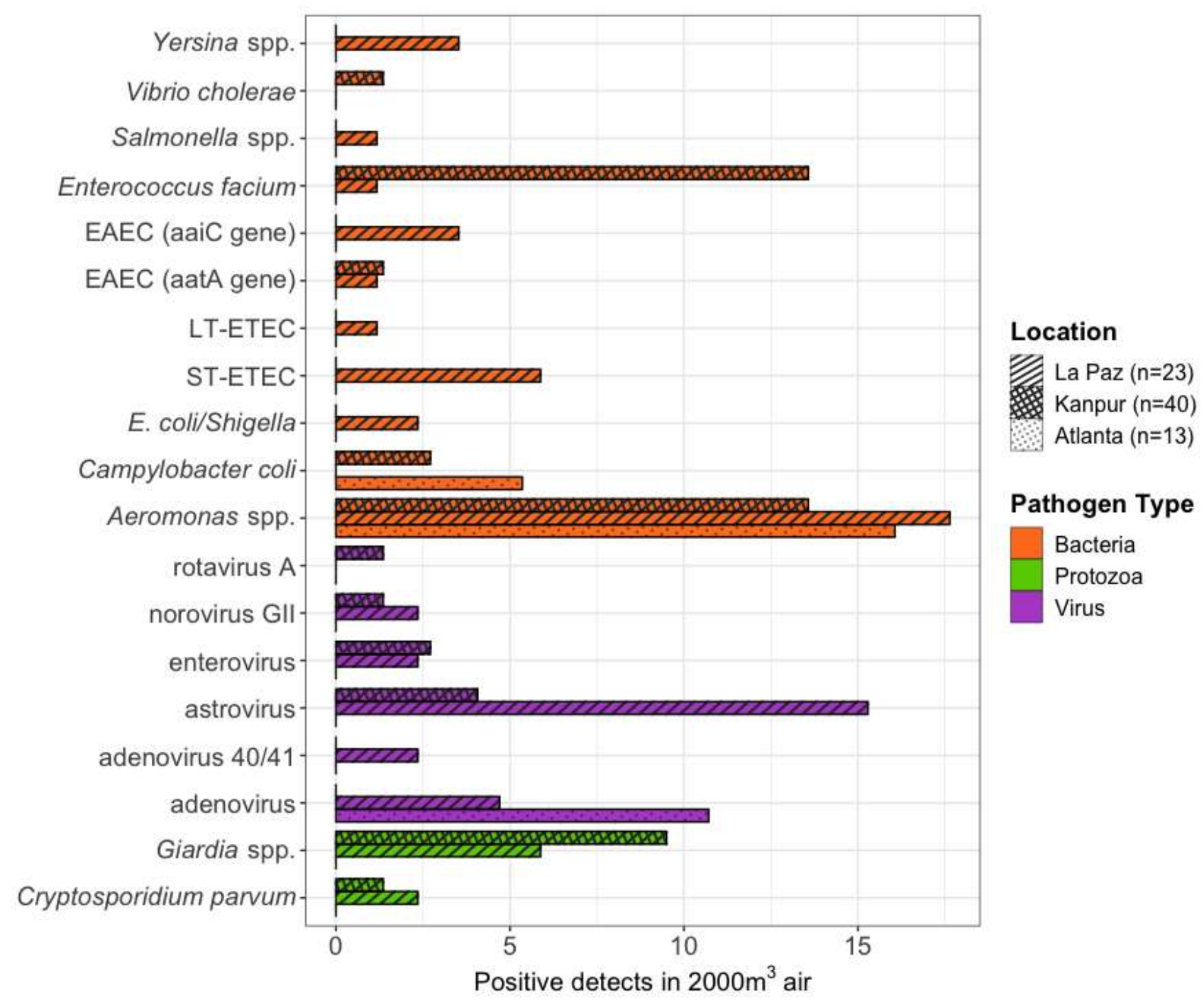

Figure S1. TAC detection of enteric pathogen targets in $2000 \mathrm{~m}^{3}$ air, stratified by location and pathogen group.

Molecular detection of $\boldsymbol{E}$. coli (qPCR and ddPCR), Bolivia. We detected an average of $2.0 \times 10^{4}( \pm$ $\left.3.3 \times 10^{4}\right) \mathrm{gc}_{\text {per }} \mathrm{m}_{\text {air }}(\mathrm{n}=75)$ via ddPCR. Through $\mathrm{qPCR}$, we detected any E. coli species in $31 \%$ of samples $(n=26)$. Of the matched qPCR and ddPCR samples $(n=26)$, we detected E. coli through qPCR in $23 \%$ of samples that had detectable E. coli through ddPCR (Figure S2). We detected culturable E. coli in $23 \%$ of the samples with detectable $E$. coli when we had data from both methods. 

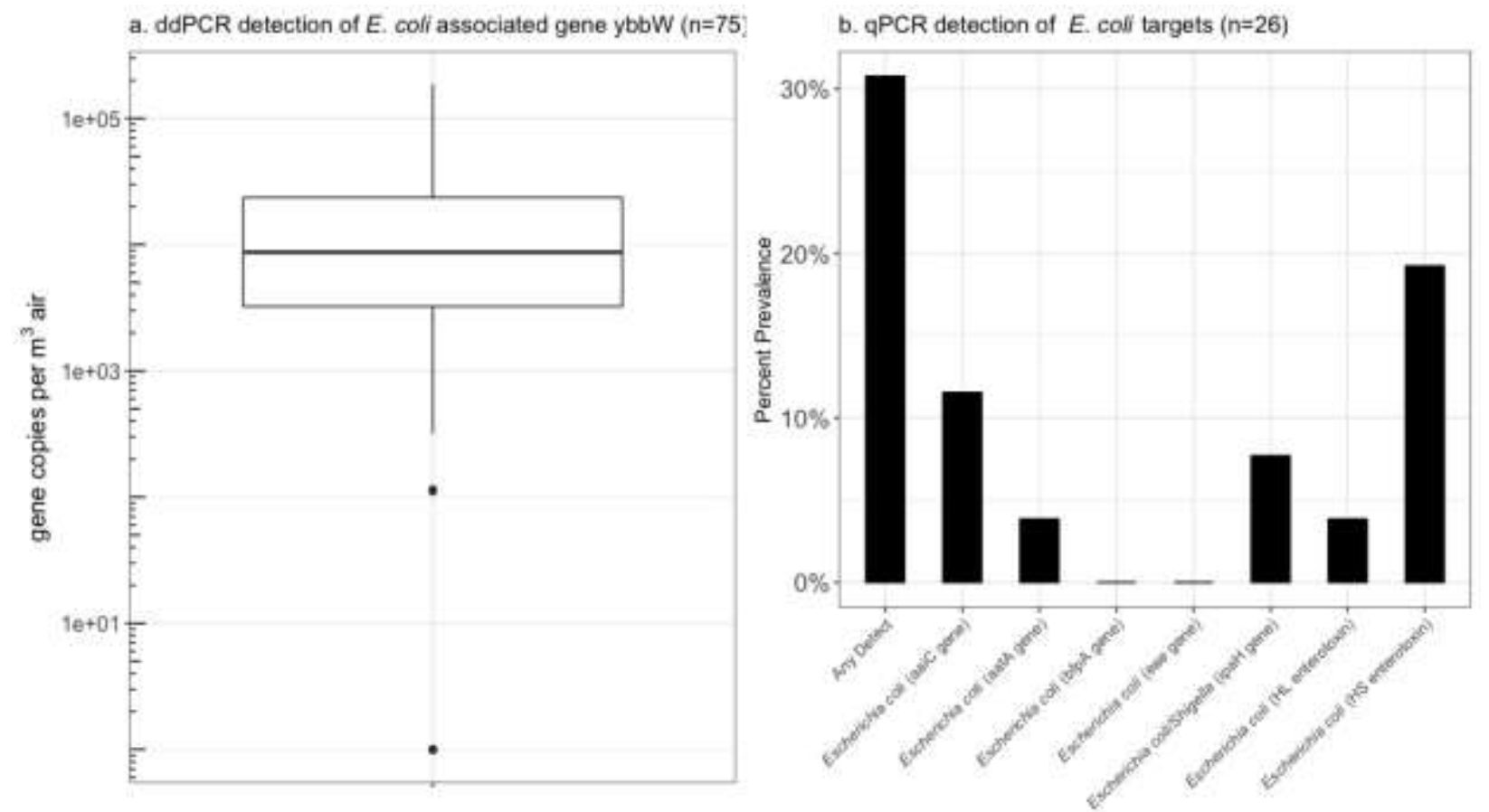

Figure S2. (a) We detected through ddPCR the E. coli associated gene ybbW in La Paz. The target was present in $92 \%$ of samples. (b) We detected through qPCR multiple E. coli strains and multiple gene targets.
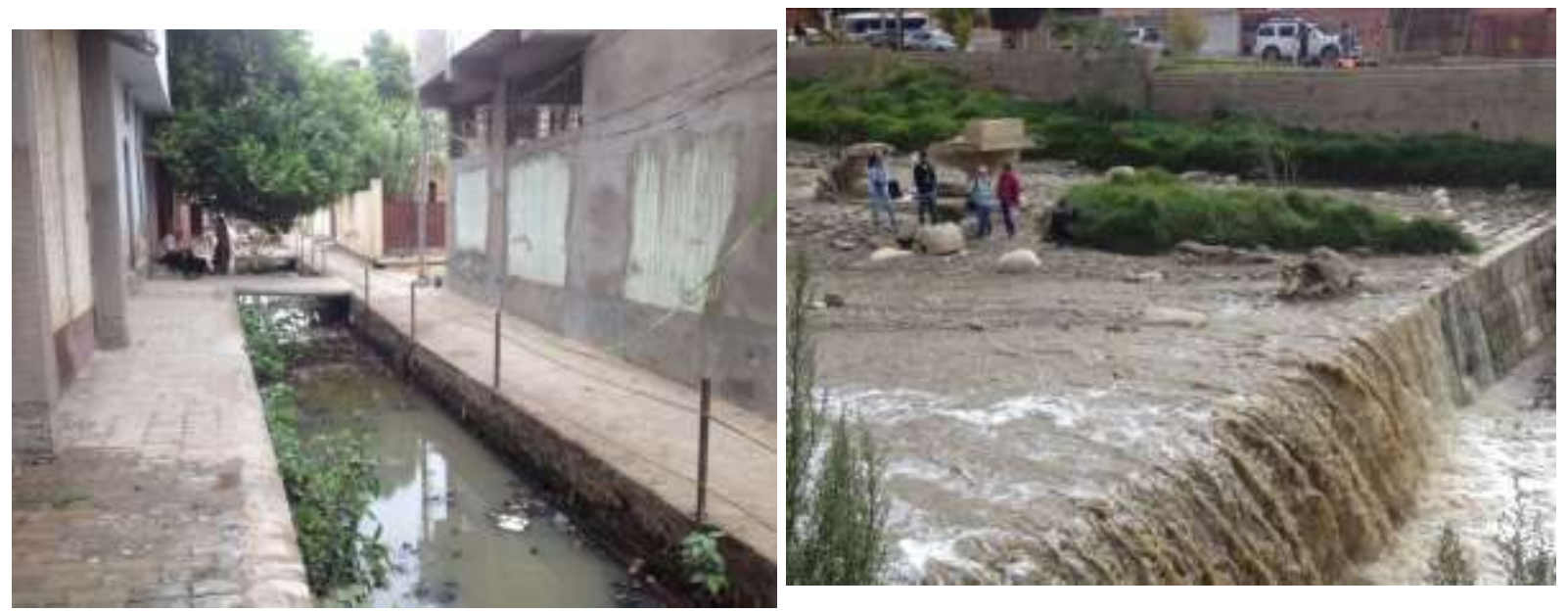

Figure S3. Typical open wastewater canals in Kanpur, India (left) and La Paz, Bolivia (right). Photos by Joe Brown. 


\section{Open waste canal water samples.}

To confirm fecal contamination in environmental water sources adjacent to bioaerosol sampling sites in Kanpur, India, we collected $45 \mathrm{~mL}$ liquid grab samples from nearby surface waters at 11 OWCs. We analyzed OWC samples via the Luminex xTAG Gastrointestinal-Pathogen Panel (GPP) on Luminex MagPix device (Thermo Scientific ${ }^{\mathrm{TM}}$, USA). This multiplex, RT-PCR based assay simultaneously detects the presence/absence of the following microbes that represent important enteric pathogens globally and indicate potential fecal contamination ${ }^{56-58}$ : adenovirus 40/41, rotavirus A, norovirus GI/GII, Salmonella spp.(including serovars Typhi and Paratyphi), Campylobacter spp. (C. jejuni, C. coli, C. lari), Shigella spp. (S.boydii, S. sonnei, S. flexneri, S. dysenteriae), Clostridium difficile Toxin A/B, enterotoxigenic Escherichia coli (ETEC) LT/ST, E. coli O157, Shiga-like toxin-producing E. coli (STEC) stx1/stx2, Yersinia enterocolitica, Vibrio cholerae, Giardia duodenalis, Entamoeba histolytica, and Cryptosporidium spp. (C.parvum, C. hominis). In La Paz, we collected $4100 \mathrm{~mL}$ grab samples from 3 sampling sites on the Choqueyapu river. We analyzed these samples via TAC qPCR (Table S4).

Table S4: Presence in OWCs of enteric pathogens tested via the Luminex xTAG GPP multiplex assay.

\begin{tabular}{|c|c|c|c|c|c|}
\hline \multicolumn{3}{|c|}{ Kanpur } & \multicolumn{3}{|c|}{$\mathrm{LaPaz}$} \\
\hline $\begin{array}{c}\text { Number } \\
\text { of } \\
\text { Samples }\end{array}$ & Positive Detects & Method & $\begin{array}{c}\text { Number of } \\
\text { Samples }\end{array}$ & Positive detects & Method \\
\hline 11 & $\begin{array}{c}\text { Giardia spp. (9), ETEC (5), } \\
\text { Campylobacter spp. (4), } \\
\text { Salmonella spp. (1), Norovirus } \\
\text { (1) }\end{array}$ & GPP & 4 & $\begin{array}{c}\text { Pan-adenovirus (2), } \\
\text { adenovirus 40/41 (1), pan- } \\
\text { astrovirus (3), pan- } \\
\text { enterovirus (1), norovirus } \\
\text { GI (2), norovirus GII (1), } \\
\text { rotavirus A (1), sapovirus } \\
\text { I/II/IV (2), sapovirus V } \\
\text { (1), Aeromonas spp. (4), } \\
\text { EAEC (3), EPEC (1), ST- } \\
\text { ETEC (3), LT-ETEC (2), } \\
\text { EIEC/Shigella spp. (2), E. }\end{array}$ & TAC \\
\hline
\end{tabular}




\begin{tabular}{|c|c|c|c|c|c|}
\hline & & & $\begin{array}{c}\text { faecium (1), STEC (2), } \\
\text { Yersinia spp. (2), Giardia } \\
\text { duodenalis (4) }\end{array}$ & \\
\hline
\end{tabular}

\section{REFERENCES: Supporting Information}

(1) Kodani, M.; Winchell, J. M. Engineered Combined-Positive-Control Template for Real-Time Reverse Transcription-PCR in Multiple-Pathogen-Detection Assays. J. Clin. Microbiol. 2012, 50 (3), 1057-1060.

(2) Capone, D.; Berendes, D.; Cumming, O.; Knee, J.; Nalá, R.; Risk, B. B.; Stauber, C.; Zhu, K.; Brown, J. Analysis of Fecal Sludges Reveals Common Enteric Pathogens in Urban Maputo, Mozambique. Environ. Sci. Technol. Lett. 2020, 7 (12), 889-895.

(3) Capone, D.; Chigwechokha, P.; de los Reyes, F. L.; Holm, R. H.; Risk, B. B.; Tilley, E.; Brown, J. Impact of Sampling Depth on Pathogen Detection in Pit Latrines. PLoS Negl. Trop. Dis. 2021, 15 (3), 1-13.

(4) Liu, J.; Gratz, J.; Amour, C.; Kibiki, G.; Becker, S.; Janaki, L.; Verweij, J. J.; Taniuchi, M.; Sobuz, S. U.; Haque, R.; Haverstick, D.; Houpt, E.. A Laboratory-Developed Taqman Array Card for Simultaneous Detection of 19 Enteropathogens. J. Clin. Microbiol. 2013, 51 (2), 472-480.

(5) Igbinosa, I. H.; Igumbor, E. U.; Aghdasi, F.; Tom, M.; Okoh, A. I. Emerging Aeromonas Species Infections and Their Significance in Public Health. Sci. World J. 2012, 2012.

(6) Cunningham, S. A.; Sloan, L. M.; Nyre, L. M.; Vetter, E. A.; Mandrekar, J.; Patel, R. Three-Hour Molecular Detection of Campylobacter, Salmonella, Yersinia, and Shigella Species in Feces with Accuracy as High as That of Culture. J. Clin. Microbiol. 2010, 48 (8), 2929-2933.

(7) Roux, F.; Sproston, E.; Rotariu, O.; MacRae, M.; Sheppard, S. K.; Bessel, P.; Smith-Palmer, A.; Cowden, J.; Maiden, M. C. J.; Forbes, K. J.; Strachan, N. Elucidating the Aetiology of Human Campylobacteri Coli Infections. PLoS One 2013, 8 (5).

(8) Houser, B. A.; Hattel, A. L.; Jayarao, B. M. Real-Time Multiplex Polymerase Chain Reaction Assay for Rapid Detection of Clostridium Difficile Toxin-Encoding Strains. Foodborne Pathog. Dis. 2010, 7 (6), 719-726.

(9) Di Bella, S.; Ascenzi, P.; Siarakas, S.; Petrosillo, N.; di Masi, A. Clostridium Difficile Toxins A and B: Insights into Pathogenic Properties and Extraintestinal Effects. Toxins (Basel). 2016, 8 (5), 1-25.

(10) Diaz, M. H.; Waller, J. L.; Theodore, M. J.; Patel, N.; Wolff, B. J.; Benitez, A. J.; Morris, T.; Raghunathan, P. L.; Breiman, R. F.; Whitney, C. G.; Blau, D.; Winchell, J. Development and 
Implementation of Multiplex TaqMan Array Cards for Specimen Testing at Child Health and Mortality Prevention Surveillance Site Laboratories. 2019, 69 (Suppl 4), 311-321.

(11) Cohen, S. H.; Tang, Y. J.; Silva, J. Analysis of the Pathogenicity Locus in Clostridium Difficile Strains. J. Infect. Dis. 2000, 181 (2), 659-663.

(12) Bamidele, O.; Jiang, Z. D.; Dupont, H. Occurrence of Putative Virulence-Related Genes, AatA, AggR and AaiC, of Enteroaggregative Escherichia Coli (EAEC) among Adults with Travelers' Diarrhea Acquired in Guatemala and Mexico. Microb. Pathog. 2019, 128 (December 2018), 9799.

(13) Boisen, N.; Struve, C.; Scheutz, F.; Krogfelt, K. A.; Nataro, J. P. New Adhesin of Enteroaggregative Escherichia Coli Related to the Afa/Dr/AAF Family. Infect. Immun. 2008, 76 (7), 3281-3292.

(14) Thiem, V. D.; Sethabutr, O.; Seidlein, L. von; Tung, T. Van; Canh, D. G.; Chien, B. T.; Tho, L. H.; Lee, H.; Houng, H.; Hale, T. L.; Clemens, J.; Mason, C.; Trach, D. D. Detection of Shigella by a PCR Assay Targeting the IpaH Gene Suggests Increased Prevalence of Shigellosis in Nha Trang, Vietnam. J. Clin. Microbiol. 2004, 42 (5), 2031-2035.

(15) Van Den Beld, M. J. C.; Reubsaet, F. A. G. Differentiation between Shigella, Enteroinvasive Escherichia Coli (EIEC) and Noninvasive Escherichia Coli. Eur. J. Clin. Microbiol. Infect. Dis. 2012, 31 (6), 899-904.

(16) Ryan, K. J.; Ray, G. C. Sherris Medical Microbiology: An Introduction to Infectious Diseases, 4th ed.; McGraw-Hill Medical, 2003.

(17) Jerse, A. E.; Kaper, J. B. The Eae Gene of Enteropathogenic Escherichia Coli Encodes a 94Kilodalton Membrane Protein, the Expression of Which Is Influenced by the EAF Plasmid. Infect. Immun. 1991, 59 (12), 4302-4309.

(18) Nataro, J. P.; Kaper, J. B. Diarrheagenic Escherichia Coli. Clin. Microbiol. Rev. 1998, 11 (1), 142201.

(19) Hidaka, A.; Hokyo, T.; Arikawa, K.; Fujihara, S.; Ogasawara, J.; Hase, A.; Hara-Kudo, Y.; Nishikawa, Y. Multiplex Real-Time PCR for Exhaustive Detection of Diarrhoeagenic Escherichia Coli. J. Appl. Microbiol 2009, 106 (2), 410-420.

(20) Moseley, S. L.; Echeverria, P.; Seriwatana, J.; Tirapat, C.; Chaicumpa, W.; Sakuldaipeara, T.; Falkow, S. Identification of Enterotoxigenic Escherichia Coli by Colony Hybridization Using Three Enterotoxin Gene Probes. J. Infect. Dis. 1982, 145 (6), 863-869.

(21) Eng, S. K.; Pusparajah, P.; Ab Mutalib, N. S.; Ser, H. L.; Chan, K. G.; Lee, L. H. Salmonella: A Review on Pathogenesis, Epidemiology and Antibiotic Resistance. Front. Life Sci. 2015, 8 (3), 284-293. 
(22) Melton-Celsa, A. R. Shiga Toxin (Stx) Classification, Structure, and Function. Microbiol. Spectr. 2014, 2 (4), 1-21.

(23) Chowdhury, G.; Joshi, S.; Bhattacharya, S.; Sekar, U.; Birajdar, B.; Bhattacharyya, A.; Shinoda, S.; Ramamurthy, T. Extraintestinal Infections Caused by Non-Toxigenic Vibrio Cholerae NonO1/Non-O139. Front. Microbiol. 2016, 7 (FEB), 1-5.

(24) Liu, J.; Gratz, J.; Amour, C.; Nshama, R.; Walongo, T.; Maro, A.; Mduma, E.; Platts-Mills, J.; Boisen, N.; Nataro, J.; Haverstick, D.; Kabir, F.; Lerthsethtakarn, P.; Silapong, S.;

Jeamwattanalert, P.; Bodhidatta, L.; Mason, C.; Begum, S.; Haque, R.; Praharaj, I.; Kang, G.; Houpt, E. Optimization of Quantitative PCR Methods for Enteropathogen Detection. PLoS One 2016, $11(6), 1-11$.

(25) Kaper, J. B.; Moseley, S. L.; Falkow, S. Molecular Characterization of Environmental and Nontoxigenic Strains of Vibrio Cholerae. Infect. Immun. 1981, 32 (2), 661-667.

(26) Liu, J.; Gratz, J.; Maro, A.; Kumburu, H.; Kibiki, G.; Taniuchi, M.; Howlader, A. M.; Sobuz, S. U.; Haque, R.; Talukder, K. A.; Qureshi, S.; Zaidi, A.; Haverstick, D.; Houpt, E. Simultaneous Detection of Six Diarrhea-Causing Bacterial Pathogens with an In-House PCR-Luminex Assay. J. Clin. Microbiol 2012, 50 (1), 98-103.

(27) Jothikumar, N.; Cromeans, T. L.; Hill, V. R.; Lu, X.; Sobsey, M. D.; Erdman, D. D. Quantitative Real-Time PCR Assays for Detection of Human Adenoviruses and Identification of Serotypes 40 and 41. Appl. Environ. Microbiol. 2005, 71 (6), 3131-3136.

(28) Liu J.; Platts-Mills J.; Juma J.; Kabir F.; Nkeze J, Okoi C.; Operario D.; Uddin J.; Ahmed S.; Alonso P.; Antonio M.; Becker S.; Blackwelder W.; Breiman RF.; Faruque A.; Fields B.; Gratz J.; Haque R.; Hossain A.; Hossain M.; Jarju S.; Qamar F.; Iqbal N.; Kwambana B.; Mandomando I.; McMurry T.; Ochieng C.; Ochieng J.; Ochieng M.; Onyango C.; Panchalingam S.; Kalam A.; Aziz F.; Qureshi S.; Ramamurthy T.; Roberts J.; Saha D.; Sow S.; Stroup S.; Sur D.; Tamboura B.; Taniuchi M.; Tennant S.; Toema D.; Wu Y.; Zaidi A.; Nataro JP.; Kotloff K.; Levine M.; Houpt E.

Use of Quantitative Molecular Diagnostic methods to identify causes of diarrhoea in children: a reanalysis of the GEMS case-control study. Lancet. 2016, 388(10051), 1291-1301.

(29) Ghebremedhin, B. Human Adenovirus: Viral Pathogen with Increasing Importance. Eur. J. Microbiol. Immunol. 2014, 4 (1), 26-33.

(30) Liu, J.; Kibiki, G.; Maro, V.; Maro, A.; Kumburu, H.; Swai, N.; Taniuchi, M.; Gratz, J.; Toney, D.; Kang, G.; Houpt, E. Multiplex Reverse Transcription PCR Luminex Assay for Detection and Quantitation of Viral Agents of Gastroenteritis. J. Clin. Virol 2011, 50 (4), 308-313.

(31) Bosch, A.; Pintó, R. M.; Guix, S. Human Astroviruses. Clin. Microbiol. Rev. 2014, 27 (4), 1048 
1074.

(32) Baggen, J.; Thibaut, H. J.; Strating, J. R. P. M.; Van Kuppeveld, F. J. M. The Life Cycle of NonPolio Enteroviruses and How to Target It. Nat. Rev. Microbiol. 2018, 16 (6), 368-381.

(33) Jothikumar, N.; Lowther, J. A.; Henshilwood, K.; Lees, D. N.; Hill, V. R.; Vinjé, J. Rapid and Sensitive Detection of Noroviruses by Using TaqMan-Based One-Step Reverse TranscriptionPCR Assays and Application to Naturally Contaminated Shellfish Samples. Appl. Environ.

Microbiol. 2005, 71 (4), 1870-1875.

(34) Kageyama, T.; Kojima, S.; Shinohara, M.; Uchida, K.; Fukushi, S.; Hoshino, F. B.; Takeda, N.; Katayama, K. Broadly Reactive and Highly Sensitive Assay for Norwalk-like Viruses Based on Real-Time Quantitative Reverse Transcription-PCR. J Clin Microbiol 2003, 41 (4), 1548-1557.

(35) Jothikumar, N.; Kang, G.; Hill, V. R. Broadly Reactive TaqMan® Assay for Real-Time RT-PCR Detection of Rotavirus in Clinical and Environmental Samples. J. Virol. Methods 2009, 155 (2), $126-131$.

(36) Oka, T.; Wang, Q.; Katayama, K.; Saifb, L. J. Comprehensive Review of Human Sapoviruses. Clin. Microbiol. Rev. 2015, 28 (1), 32-53.

(37) Jothikumar, N.; da Silva, A. J.; Moura, I.; Qvarnstrom, Y.; Hill, V. R. Detection and Differentiation of Cryptosporidium Hominis and Cryptosporidium Parvum by Dual TaqMan Assays. J. Med. Microbiol. 2008, 57 (9), 1099-1105.

(38) Verweij, J. J.; Blangé, R. A.; Templeton, K.; Schinkel, J.; Brienen, E. A. T.; van Rooyen, M. A. A.; van Lieshout, L.; Polderman, A.; M. Simultaneous Detection of Entamoeba Histolytica, Giardia Lamblia, and Cryptosporidium Parvum in Fecal Samples by Using Multiplex Real-Time PCR. J. Clin. Microbiol 2004, 42 (3), 1220-1223.

(39) Pilotte, N.; Papaiakovou, M.; Grant, J. R.; Bierwert, L. A.; Llewellyn, S.; McCarthy, J. S.; Williams, S. A. Improved PCR-Based Detection of Soil Transmitted Helminth Infections Using a Next-Generation Sequencing Approach to Assay Design. PLoS Negl. Trop. Dis. 2016, 10 (3).

(40) Wiria, A. E.; Prasetyani, M. A.; Hamid, F.; Wammes, L. J.; Lell, B.; Ariawan, I.; Uh, H. W.; Wibowo, H.; Djuardi, Y.; Wahyuni, S.; Sutano, I.; May, L.; Luty, A.; Verweij.; Sartano, E.; Yazdanbakhsh, M.; Supali, T. Does Treatment of Intestinal Helminth Infections Influence Malaria? Background and Methodology of a Longitudinal Study of Clinical, Parasitological and Immunological Parameters in Nangapanda, Flores, Indonesia (ImmunoSPIN Study). BMC Infect. Dis. 2010, 10 (1), 77.

(41) Rolfe, K. J.; Parmar, S.; Mururi, D.; Wreghitt, T. G.; Jalal, H.; Zhang, H.; Curran, M. D. An Internally Controlled, One-Step, Real-Time RT-PCR Assay for Norovirus Detection and Genogrouping. J. Clin. Virol. 2007, 39 (4), 318-321. 
(42) Stokdyk, J. P.; Firnstahl, A. D.; Spencer, S. K.; Burch, T. R.; Borchardt, M. A. Determining the 95\% Limit of Detection for Waterborne Pathogen Analyses from Primary Concentration to QPCR. Water Res. 2016, 96, 105-113.

(43) Bivins, A.; Lowry, S.; Murphy, H. M.; Borchardt, M.; Coyte, R.; Labhasetwar, P.; Brown, J. Waterborne Pathogen Monitoring in Jaipur, India Reveals Potential Microbial Risks of Urban Groundwater Supply. npj Clean Water 2020, 3 (1).

(44) Taylor, S. C.; Laperriere, G.; Germain, H. Droplet Digital PCR versus QPCR for Gene Expression Analysis with Low Abundant Targets: From Variable Nonsense to Publication Quality Data. Sci. Rep. 2017, 7 (1), 1-8.

(45) Boxus, M.; Letellier, C.; Kerkhofs, P. Real Time RT-PCR for the Detection and Quantitation of Bovine Respiratory Syncytial Virus. J. Virol. Methods 2005, 125 (2), 125-130.

(46) Lin, W. S.; Cheng, C. M.; Van Khanh, T. A Quantitative PCR Assay for Rapid Detection of Shigella Species in Fresh Produce. J. Food Prot. 2010, 73 (2), 221-233.

(47) Grant, M. A.; Hu, J.; Jinneman, K. C. Multiplex Real-Time PCR Detection of Heat-Labile and Heat-Stable Toxin Genes in Enterotoxigenic Escherichia Coli. J. Food Prot. 2006, 69 (2), 412 416.

(48) Best, E. L.; Powell, E. J.; Swift, C.; Grant, K. A.; Frost, J. A. Applicability of a Rapid Duplex Real-Time PCR Assay for Speciation of Campylobacter Jejuni and Campylobacter Coli Directly from Culture Plates. FEMS Microbiol. Lett. 2003, 229 (2), 237-241.

(49) Malorny, B.; Paccassoni, E.; Fach, P.; Bunge, C.; Martin, A.; Helmuth, R. Diagnostic Real-Time PCR for Detection of Salmonella in Food. Appl. Environ. Microbiol. 2004, 70 (12), 7046-7052.

(50) Hoorfar, J.; Ahrens, P.; Radstrom, P. Automated 5' Nuclease PCR Assay for Identification of Salmonella Enterica. J. Clin. Microbiol. 2000, 38 (9), 3429-3435.

(51) Walker, D. I.; McQuillan, J.; Taiwo, M.; Parks, R.; Stenton, C. A.; Morgan, H.; Mowlem, M. C.; Lees, D. N. A Highly Specific Escherichia Coli QPCR and Its Comparison with Existing Methods for Environmental Waters. Water Res. 2017, 126, 101-110.

(52) Baque, R. H.; Gilliam, A. O.; Robles, L. D.; Jakubowski, W.; Slifko, T. R. A Real-Time RT-PCR Method to Detect Viable Giardia Lamblia Cysts in Environmental Waters. Water Res. 2011, 45 (10), 3175-3184.

(53) Liu, J.; Kabir, F.; Manneh, J.; Lertsethtakarn, P.; Begum, S.; Gratz, J.; Becker, S. M.; Operario, D. J.; Taniuchi, M.; Janaki, L.; Platts-Mills, J.; Haverstick, D.; Kabir, M.; Sobuz, S.; Nakjarung, K.; Sakpaisal, P.; Silapong, S.; Bodhidatta, L.; Qureshi, S.; Kalam, A.; Saidi, Q.; Swai, N.; Mujaga, B.; Maro, A.; Kwambana, B.; Dione, M.; Antonio, M.; Kibiki, G.; Mason, C.; Haque, R.; Iqbal, N.; Zaidi, A.; Houpt, E. Development and Assessment of Molecular Diagnostic Tests for 15 
Enteropathogens Causing Childhood Diarrhoea: A Multicentre Study. Lancet Infect. Dis. 2014, 14 (8), 716-724.

De Leon, R.; Shieh, C.; Baric, R. S.; Sobsey, M. D. Detection of Enteroviruses and Hepatitis a Virus. In Proceedings of the 1990 Water Quality Technology Conference.; American Water Works Association: Denver, 1990; pp 833-853.

Monpoeho, S.; Dehee, A.; Mignotte, B.; Schwartzbrod, L.; Marechal, V.; Nicolas, J.-C.; Billaudel, S.; Ferre, V. Quantification of Enterovirus RNA in Sludge Samples Using Single Tube Real-Time RT-PCR. Biotechniques 2000, 29 (1), 88-93.

Brown, J.; Cumming, O.; Bartram, J.; Cairncross, S.; Ensink, J.; Holcomb, D.; Knee, J.; Kolsky, P.; Liang, K.; Liang, S.; Nala, R.; Norman, G.; Rheingans, R.; Stewart, J.; Zavale, O.; Zuin, V.; Schmidt, W. A Controlled, before-and-after Trial of an Urban Sanitation Intervention to Reduce Enteric Infections in Children: Research Protocol for the Maputo Sanitation (MapSan) Study, Mozambique. BMJ Open 2015, 5 (6), 1-12.

(57) Claas, E. C.; Burnham, C. A. D.; Mazzulli, T.; Templeton, K.; Topin, F. Performance of the XTAG® Gastrointestinal Pathogen Panel, a Multiplex Molecular Assay for Simultaneous Detection of Bacterial, Viral, and Parasitic Causes of Infectious Gastroenteritis. J. Microbiol. Biotechnol. 2013, 23 (7), 1041-1045.

(58) Kotloff, K. L.; Nataro, J. P.; Blackwelder, W. C.; Nasrin, D.; Farag, T. H.; Panchalingam, S.; Wu, Y.; Sow, S. O.; Sur, D.; Breiman, R. F.; Faruque, A.; Zaidi A.; Saha D.; Alonso P.; Tamboura B.; Sanogo D.; Onwuchekwa U.; Manna B.; Ramamurthy T.; Kanungo S.; Ochieng J.; Omore R.; Oundo J.; Hossain A.; Das SK.; Ahmed S.; Qureshi S.; Quadri F.; Adegbola R.; Antonio M.; Hossain M.; Akinsola A.; Mandomando I.; Nhampossa T.; Acácio S.; Biswas K.; O'Reilly C.; Mintz E.; Berkeley L.; Muhsen K.; Sommerfelt H.; Robins-Browne R.; Levine M. Burden and Aetiology of Diarrhoeal Disease in Infants and Young Children in Developing Countries (the Global Enteric Multicenter Study, GEMS): A Prospective, Case-Control Study. Lancet 2013, 382 (9888), 209-222. 